\title{
Pre-Type 1 (insulin-dependent) diabetes: common endocrinological course despite immunological and immunogenetic heterogeneity
}

\author{
S. Srikanta ${ }^{1,4,6}$, O.P. Ganda ${ }^{1,5,6}$, R.A.Jackson ${ }^{1,4,6}$, S.J. Brink ${ }^{1}$, E. Fleischnick ${ }^{2}$, E. Yunis ${ }^{3,6}$, C. Alper ${ }^{2,6}$, \\ J.S. Soeldner ${ }^{1,4,6}$ and G.S. Eisenbarth $1,4,6$ \\ ${ }^{1}$ Joslin Diabetes Center, ${ }^{2}$ Center for Blood Research, ${ }^{3}$ Dana-Farber Cancer Institute, ${ }^{4}$ Brigham and Women's Hospital, \\ ${ }^{5}$ New England Deaconess Hospital, ${ }^{6}$ Harvard Medical School, Boston, Massachusetts, USA
}

\begin{abstract}
Summary. In an ongoing prospective study 32 individuals have been evaluated for insulin secretory dynamics, islet cell antibodies and HLA antigens, during the preclinical phase of Type 1 diabetes mellitus. Twenty-four out of the 32 subjects were islet cell antibody-positive. To date, 14 subjects ( 10 islet cell antibody-positive, four islet cell antibody-negative) have progressed to develop overt diabetes. Several patterns of HLA-DR expression were noted (DR3/DR4, DR3/DR3,
\end{abstract}

$\mathrm{DR} 3 / \mathrm{x}, \quad \mathrm{DR} 3 / \mathrm{DR} 1, \quad \mathrm{DR} 4 \mathrm{x}, \mathrm{DR} 4 / \mathrm{DR} 7, \mathrm{DR}$ /DR7, $\mathrm{DR} 1 / \mathrm{DR} 7$ and DR1/DR2). Irrespective of differences in islet cell antibody status or HLA-DR alleles, pre-diabetic individuals exhibited a similar slow course of progressive $\beta$-cell dysfunction.

Key words: Type 1 diabetes, islet cell antibody, HLA antigens, heterogeneity.
There is increasing evidence that Type 1 (insulin-dependent) diabetes is a slow autoimmune disease [1,2]. During the preclinical phase, we have described progressive loss of first phase insulin release in response to intravenous glucose in five monozygotic twins, one first degree relative and three subjects who presented with transient glycosuria [3-6]. Following these studies, we have screened first degree relatives of Type 1 diabetic patients for cytoplasmic anti-islet antibodies and have studied insulin secretion of the antibody-positive relatives. In addition, we have evaluated patients referred to us with a history of transient glycosuria or asymptomatic mild glucose intolerance. So far, we have identified and studied 32 non-obese individuals; 14 have developed overt diabetes and 18 are non-diabetic, but fall into one or more high risk categories (islet cell antibody-positive and/or Ia $\mathrm{T}$ cell-positive and/or progressive and profound abnormality of first phase insulin secretion). In this study, we present evidence that all patients progressively lose their first phase insulin release prior to overt diabetes, despite differences in DR alleles expressed and/or detectable cytoplasmic anti-islet cell antibodies.

\section{Subjects and methods}

\section{Subjects}

The following groups of subjects at increased risk for the development of Type 1 diabetes were included in this analysis: (1) monozygotic twins, initially discordant for Type 1 diabetes $(n=24$, maximum follow-up 22 years); (2) first degree relatives of Type 1 diabetic patients ( $n=70$, maximum follow-up 22 years); (3) first degree relatives of Type 1 diabetic patients in whom the follow-up has been of relatively short duration ( $n=700$, maximum follow-up 18 months), and (4) patients referred for the evaluation of asymptomatic hyperglycaemia or transient glycosuria $(n=6)$.

The proband was classified as having Type 1 diabetes, primarily based on insulin dependency and ketosis-proneness under basal conditions; detection of islet cell antibodies in the index diabetic subject, presence of other autoimmune endocrinopathies and absence of obesity supported this assigment.

Coded sera stored at $-20^{\circ} \mathrm{C}$ were tested for islet cell cytoplasmic antibodies by indirect immunofluorescence using frozen sections of human pancreas. Serum samples were read independently by two observers on a scale from 0 to ++++ without knowing their origin. On average, one serum sample was screened per year of follow up.

Intravenous glucose tolerance tests were performed by infusion dextrose $(0.5 \mathrm{~g} / \mathrm{kg}$ body weight) over a $2-4 \mathrm{~min}$ period. For oral glucose tolerance tests, $100 \mathrm{~g}$ glucose was administered. Whole venous blood glucose was measured by autoanalyser (Technicon Instruments, Tarrytown, New York, USA). Serum immunoreactive insulin was measured by a double-antibody technique. Early peak insulin response to intravenous glucose was calculated as the sum of the $1 \mathrm{~min}$ and $3 \mathrm{~min}$ values. Distribution of early peak insulin response $(1 \mathrm{~min}+3 \mathrm{~min})$ during 407 intravenous glucose tolerance tests in more than 200 normal subjects (aged 8-77 years) was as follows: first percentile $46 \mathrm{mU} / \mathrm{l}$; fifth percentile $67 \mathrm{mU} / 1$; tenth percentile $81 \mathrm{mU} / 1$; fiftieth percentile $169 \mathrm{mU} / \mathrm{l}$.

\section{Results}

Of the 32 subjects included in this analysis, 24 were found to have circulating islet cell antibodies (ICA) (five twins, 16 first degree relatives and three subjects without a family history of diabetes). We found that approximately $2 \%$ of first degree relatives screened were ICA-positive. Out of the 24 ICA-positive subjects, 10 (four twins, five first degree relatives and one patient with a history of transient glycosuria) have already developed overt diabetes with fasting hyperglycaemia. 


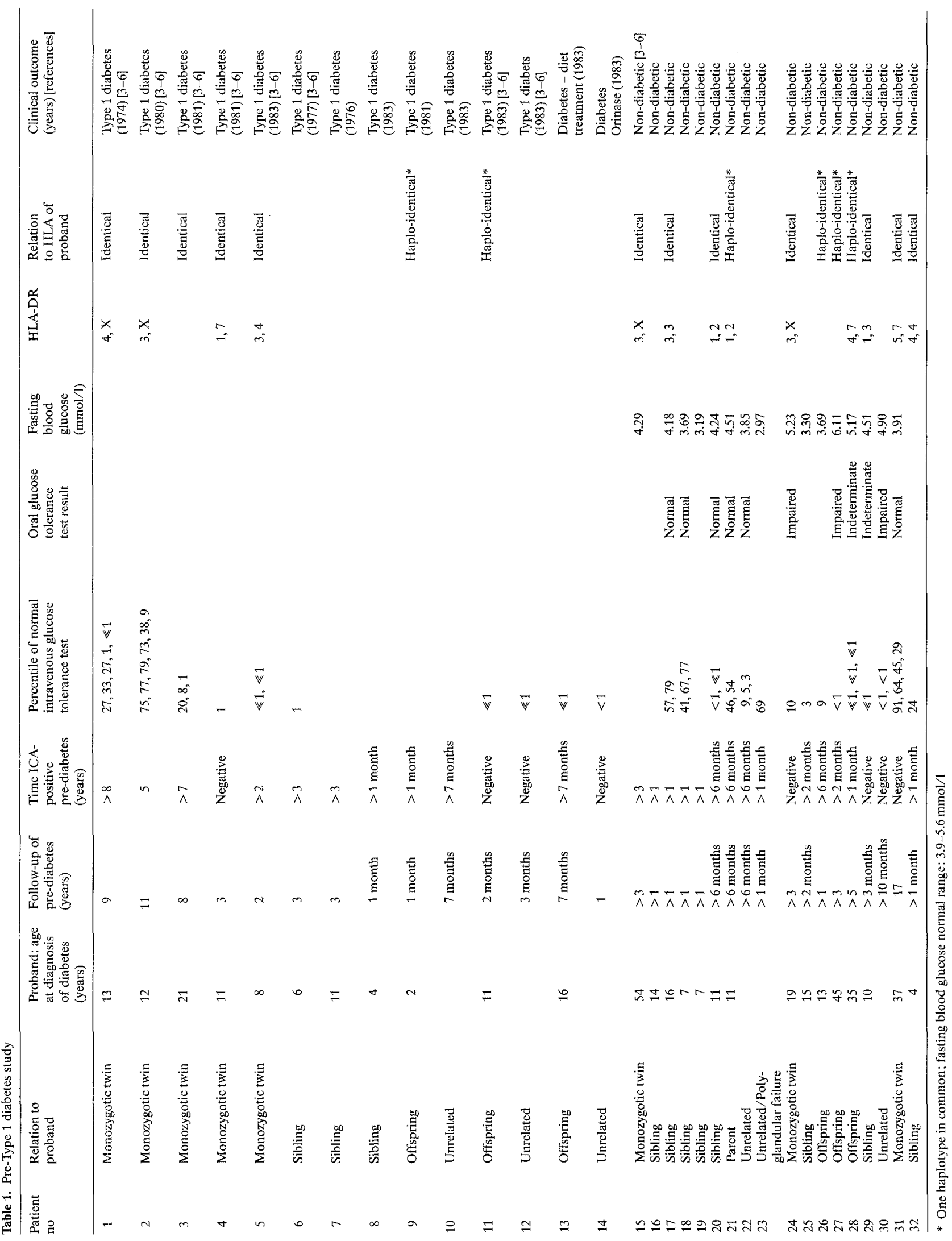


In these subjects, ICA were detected between 8 years and 1 month before the diagnosis of clinical diabetes (Table 1). It is important to note that all except one of these patients (subject 3) were ICA-positive at the initial determination. There was no evidence of transient ICA positivity (ICA persisted until and beyond the onset of overt diabetes). Among the ICA-negative subjects, who have also been tested for $\beta$-cell function with long-term follow-up (19 twins, 65 first degree relatives), only one twin (subject 4) developed overt diabetes (one other twin, subject 24 , has demonstrated impaired glucose tolerance).

The following is a summary of the features of the 'pre-diabetic' phase of Type 1 diabetes as shown by current studies of these 32 patients (Table 1 ):

(1) ICA preceded the clinical diagnosis of overt insulindependent diabetes in the majority, but not all subjects studied (subjects 4, 11,12).

(2) During the 'pre-diabetic' phase, the presence of ICA was temporally correlated with a progressive linear decline in $\beta$-cell function (subjects $1,2,3,5,20,22,31$ ).

(3) Progressive loss of first phase insulin response to intravenous glucose was a good endocrine marker of early progressive $\beta$-cell dysfunction, with a virtual absence of this insulin release in the year preceding the development of overt Type 1 diabetes (subjects 1, 3, 4, 5, 11,12).

(4) Elevations in fasting blood glucose levels and gross abnormalities in oral glucose tolerance appeared only later during the prediabetic phase; a delayed and subsequently diminished insulin response to oral glucose preceded elevations of blood glucose during tolerance testing (subjects 1, 3, 4, 5, 6, 11, 12).

(5) During the prediabetic period in all patients, there was a selectively greater decrement in insulin response to intravenous glucose, with a relatively preserved insulin release following intravenous tolbutamide, intravenous arginine, oral glucose and intravenous glucagon (subjects 1, 2, 3, 4, 5, 11, 12, 13, 14, 20, 30).

(6) Some ICA-positive subjects had stable insulin release (subjects 1, 18,21) of variable duration (subject 1).

(7) HLA-DR3 and -DR4 alleles are not essential for the phenomenon of progressive $\beta$-cell dysfunction (subjects $4,20,21,31$ ). One patient (No.20) with HLADR2/DR1 (extremely rare in Type1 diabetes) is an ICApositive sibling, HLA-identical to two brothers with Type 1 diabetes and has progressive and profound loss of first phase insulin release to intravenous glucose.

(8) Despite complete loss of first phase insulin release to intravenous glucose, some individuals still had normal oral glucose tolerance (subjects 20,28). Following this, oral glucose tolerance and insulin response have been noted to deteriorate over a period of between 7 months (subject 10 ) to more than 5 years (subject 28 ).

\section{Discussion}

These and other studies indicate that the development of Type 1 diabetes can be subdivided into several stages, including (1) genetic predisposition without evidence of active autoimmunity; (2) evidence of autoimmunity with normal insulin release; (3) progressive decline of first phase insulin release to intravenous glucose with normal blood glucose; (4) overt hyperglycaemia with some residual C-peptide secretion, and (5) complete $\beta$ cell destruction with no $\mathrm{C}$-peptide secretion. The progression of autoimmune $\beta$-cell destruction can be monitored by serial evaluation of insulin secretory dynamics. First phase insulin release stimulated by intravenous glucose is lost at a time when significant insulin secretion can be obtained following oral glucose, intravenous glucose, intravenous tolbutamide and intravenous glucagon. We believe that this linear loss of glucosestimulated insulin secretion is secondary to progressive $\beta$-cell destruction, similar to that found in studies of partially pancreatectomized rats [7].

Independent of specific HLA-DR alleles and ICA status, all the prediabitic patients seen so far have followed a similar endocrine course. Within families, sharing an HLA haplotype with the diabetic proband, but not the specific DR-type, seems to be important for the development of immunologically-mediated $\beta$-cell damage.

A screening programme for immunological markers in combination with serial measurements of $\beta$-cell function should permit the prediction of the onset of overt Type 1 diabetes in the majority of individuals destined to develop this disease. A similar strategy should facilitate the evaluation of immunotherapy initiated before the occurrence of overt Type 1 diabetes.

\section{References}

1. Irvine WJ, Gray RS, Steel JM (1980) Islet-cell antibody as a marker for early Type 1 diabetes mellitus. In: Irvine WJ (ed) Immunology of Diabetes. Teviot Scientific Publications, Edinburgh, pp 117-154

2. Gorsuch AN, Spencer KM, Lister J, McNally JM, Dean BM, Bottazzo GF, Cudworth AG (1981) Evidence for long prediabetic period in Type I (insulin-dependent) diabetes mellitus. Lancet 2: 1363-1365

3. Srikanta S, Ganda OP, Jackson RA, Gleason RE, Kalcany A, Garovoy MR, Milford EL, Carpenter CB, Soeldner JS, Eisenbarth GS (1983) Type I diabetes mellitus in monozygotic twins: chronic progressive beta cell dysfunction. Ann Int Med 99:320-326

4. Srikanta S, Ganda OP, Eisenbarth GS, Soeldner JS (1983) Islet cell antibodies and beta cell function in monzygotic triplets and twins initially discordant for Type I diabetes mellitus. N Engl J Med 308: 322-325

5. Ganda OP, Srikanta S, Brink SJ, Morris MA, Gleason RE, Soeldner IS, Eisenbarth GS (1984) Differential sensitivity to beta cell secretagogues in early Type I diabetes mellitus. Diabetes (in press)

6. Srikanta S, Ganda OP, Gleason RE, Jackson RA, Soeldner JS, Eisenbarth GS (1984) Pre-Type I diabetes: linear loss of beta cell response to intravenous glucose. Diabetes (in press)

7. Bonner-Weir S, Trent DF, Weir GC (1983) Partial pancreatectomy in the rat and subsequent defect in glucose-induced insulin release. J Clin Invest 71: 1544-1553

Dr. George S. Eisenbarth

Research Division

Joslin Diabetes Center

1 Joslin Place

Boston, MA 02215

USA 